\title{
Evaluating the Compatibilities of Some Polymer Pairs, by Viscometry
}

\author{
${ }^{1}$ Arinze, R. U., ${ }^{2}$ Eboatu, A. N., ${ }^{3}$ Dioha, I. J. and ${ }^{4}$ Odinma, S. C. \\ $1,2 \& 4$ (Department of Pure and Industrial Chemistry, Nnamdi Azikiwe University, Awka, Nigeria) \\ ${ }^{3}$ (Energy Commission of Nigeria, Garki, Abuja)
}

\begin{abstract}
Synopsis: - Solutions of polymers were mixed in pairs of varying proportions. The flow times of the solution mixtures as well as those of the homopolymers were taken at room temperature. The theoretical values of the flow times of the mixtures were compared with the observed. The deviation from the two, monitors the extent of interaction between the polymer pairs, and is seen as: PVC: NR = PP: NR > PS: NR > PP: PVC > PS: PVC > PS: PP. Reasons are adduced to explain these observations.
\end{abstract}

Keywords: - Optimal interaction, Polymer blend, PP, PS, PVC.

\section{INTRODUCTION}

Polymers like other molecules do interact with one another. The mode and degree of interaction vary depending on the structure of the polymer as well as on the environment. It is these interactions that hold polymer blends or polymer-small molecular species together. The interaction phenomena involving polymers have been studied with tools as diverse as the Infra-Red spectrometer (IR), Differential Scanning Calorimeter (DSC), Thermo Gravimetric Analyzer (TGA), the Viscometer etc $[1,2,3]$. The mechanism of interaction could be columbic or electrostatic, Vander Waals, covalent, dipole-dipole, induced dipole, London or other dispersion forces or by physical entanglement [4-5]. Whatever the mechanism, interaction could entail interlocking of chains of the components. Thus, establishing points and compositions of maximum interaction is necessary for blend formation instead of blindly mixing polymer pairs. Mixing of two or more polymers to produce blends is aimed at achieving desirable properties, without the need to synthesize special novel polymer systems [6-7]. In other words, the reason for blending, is to find two or more polymers whose mixture will have synergistic property improvement beyond those that are purely additive in effect. By this the composition uniformity approaches unity, whereas, the non-uniformity is reduced [8]. Methods commonly employed for blending include, solid-solid, solid-liquid or liquid-liquid mixing [9].

\subsection{Materials}

\section{EXPERIMENTAL}

Polystyrene (PS) and polypropylene (PP) were obtained from the Eleme Petrochemical Company, Port Harcourt, Nigeria while poly vinyl chloride (PVC) was collected from the Louis Carter Plastic Company at Nnewi, and polyisoprene or natural rubber was procured from the Rubber Research Institute of Nigeria, Benin.

\subsection{Methods}

The Billmeyer's method (9) that is, the use of the Ubbelohde viscometer in measuring liquid viscometry was adopted. Stock solutions of the polymers were prepared in appropriate solvents. The flow time of the solution was taken. Different volumes $(0.5,1.5,4.5,6.5$ and 8.5$) \mathrm{ml}$ of the adduct solutions were added in succession to $30.0 \mathrm{ml}$ of adherend solution in the ubbelohde viscometer and the flow time of each mixture taken. Similarly, flow times of solutions of the individual polymers were measured. The base mole values and base molar fractions of the solutions were calculated. The additive (theoretical) values of flow times were calculated using the Nelson's equation [10]:

$\mathrm{F}$ (theoretical) $=\mathrm{W}_{1}\left(\mathrm{f}_{1}\right)+\mathrm{W}_{2}\left(\mathrm{f}_{2}\right)$ Where $\mathrm{F}, \mathrm{W}_{1}, \mathrm{f}_{1}, \mathrm{~W}_{2}, \mathrm{f}_{2}$ refer respectively to the theoretical flow times, mole fraction for polymer 1 , flow time for pure polymer 1 , mole fraction for polymer 2 and flow time for pure polymer 2. Comparison of polymer blends was determined by calculating average deviation from additivity for each pair.

\section{RESULTS AND DISCUSSION}

In this work, flow times of the individual polymers and those of the mixtures at various ratios were taken. These are the observed, which are compared to their theoretical values, the latter being obtained using the Neilson equation [9]. Neilson maintains that in physical systems, deviation from this additive value is a measure of the extent of interaction. In practically all the polymer pairs (Figs. 1-7), there are evident deviations from 
additivity values, especially at higher concentrations of the daughter polymers. There is no doubt that there are subtle but readily perceptible differences in these degrees of interaction. This must be as a result of differences in the modes and sites of interaction.

In Figs. 1, 2, 3, 5 and 6, the observed flow times are lower than the theoretical values. This is an indication of interaction, because as macromolecules in the solution interact, they tend to be less extended, that is, more coiled together. This is manifested in the reduction in the flow time. Thus, the observations in this work do not deviate from the theoretical expectations. The case of PS: PP in Fig.4 is not easily explained in that at varying base molar ratios, the solution mixtures behave differently. At very low values of $\mathrm{PP}$, the interaction between the two is minimal. As it increases, the theoretical values are lower than the observed, indicating more extended conformations while at higher PP values, the solution mixtures starts behaving like the rest of the other pairs. The incidence of the two polymers assuming more relaxed or extended state will entail repulsive forces between them. This is difficult to explain as these hydrocarbon polymers should be compatible. May be the effect of the solvent molecules come into play. The trend of the interaction between the polymer pairs studied in solutions, as depicted in Fig.7, is :-PVC:NR = PP: NR > PS: NR > PP: PVC > PS: PVC > PS: PP.

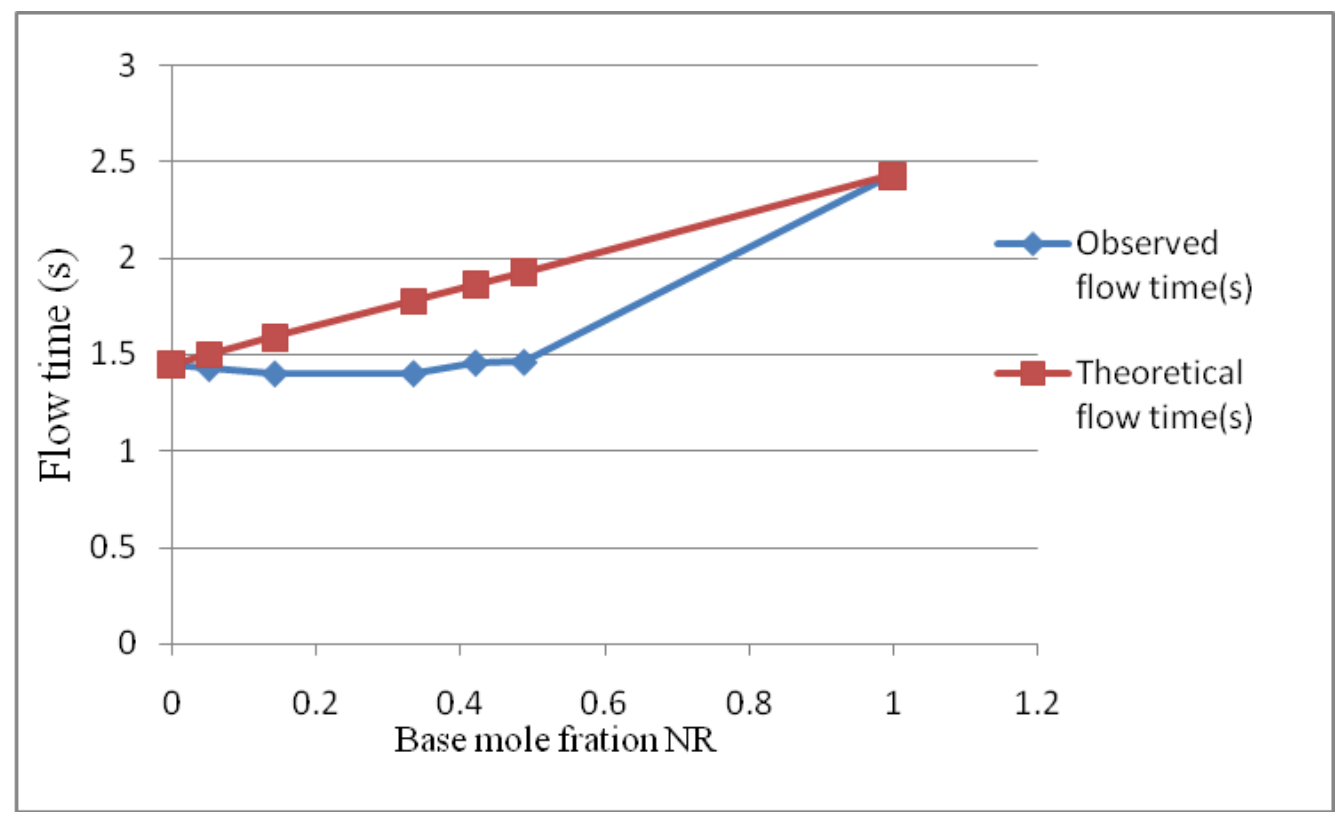

Fig. 1: Establishing the degree of interactions of PVC:NR in solution.

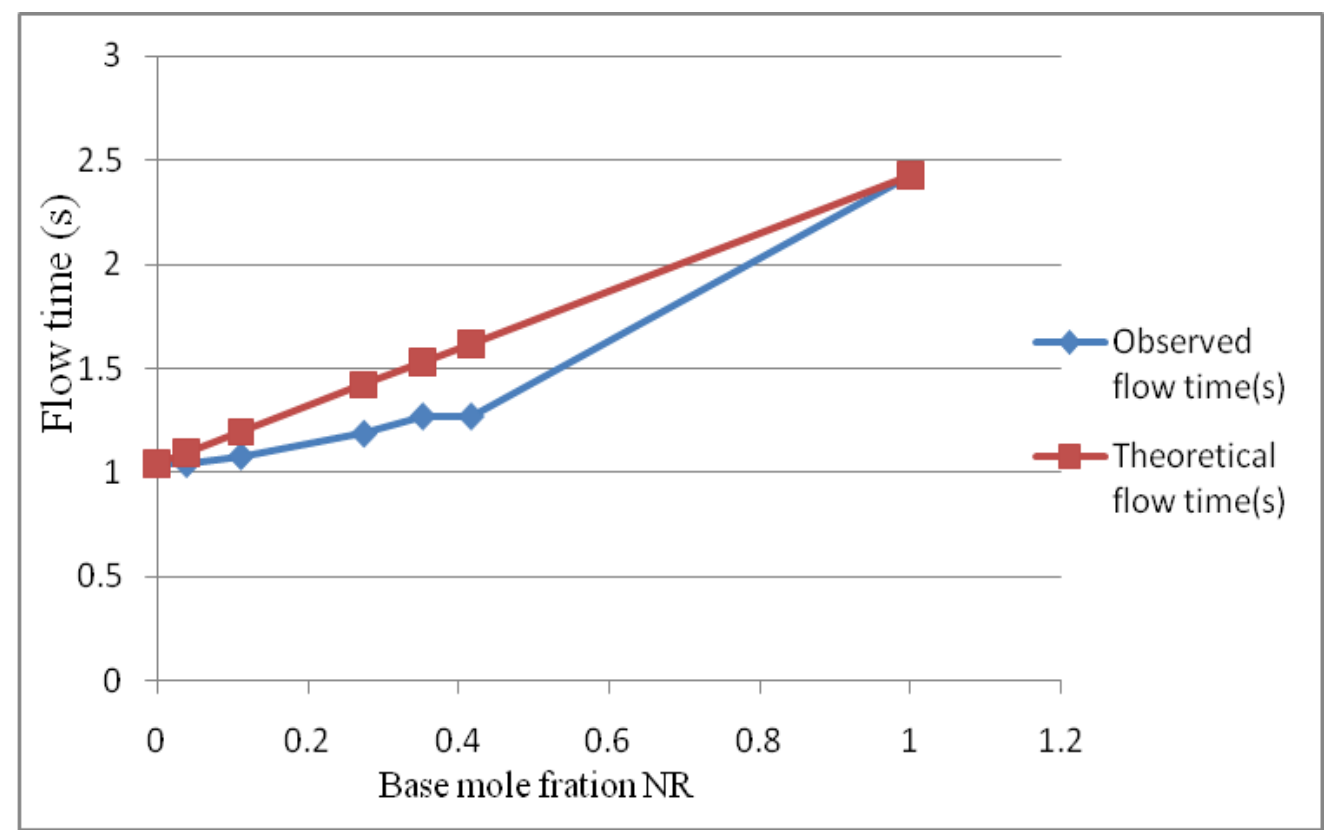

Fig.2: Establishing the degree of interactions of PS:NR in solution 


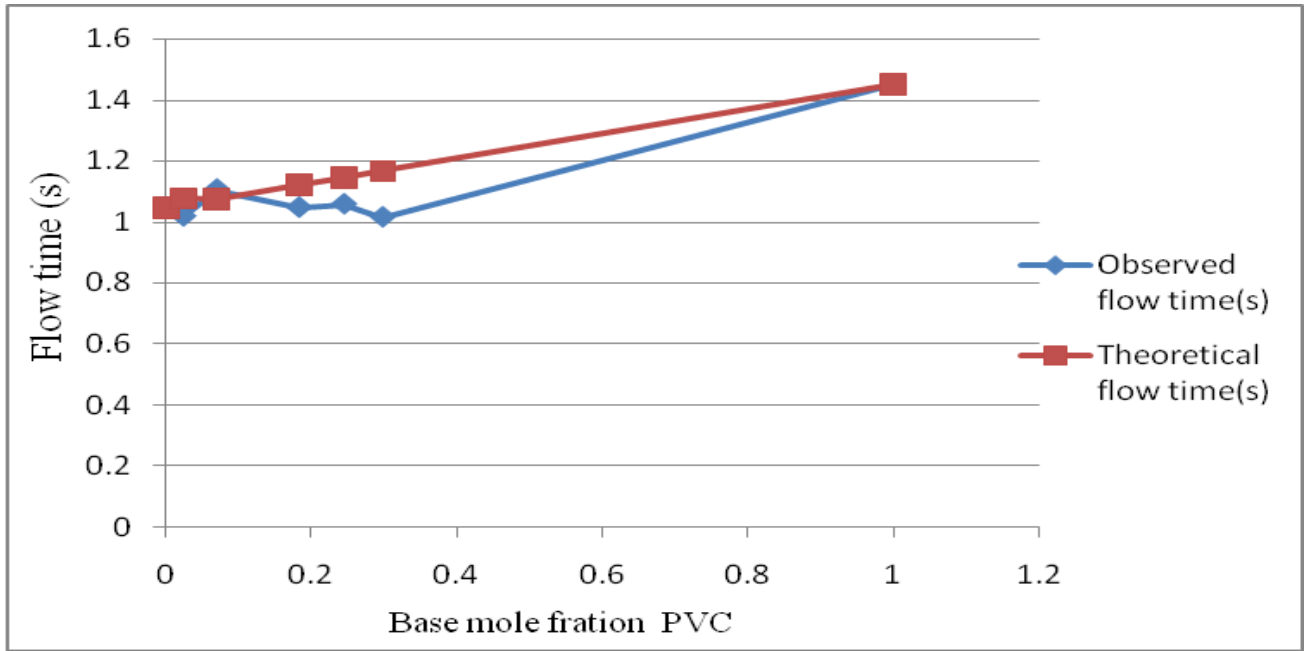

Fig.3: Establishing the degree of interactions of PS:PVC in solution

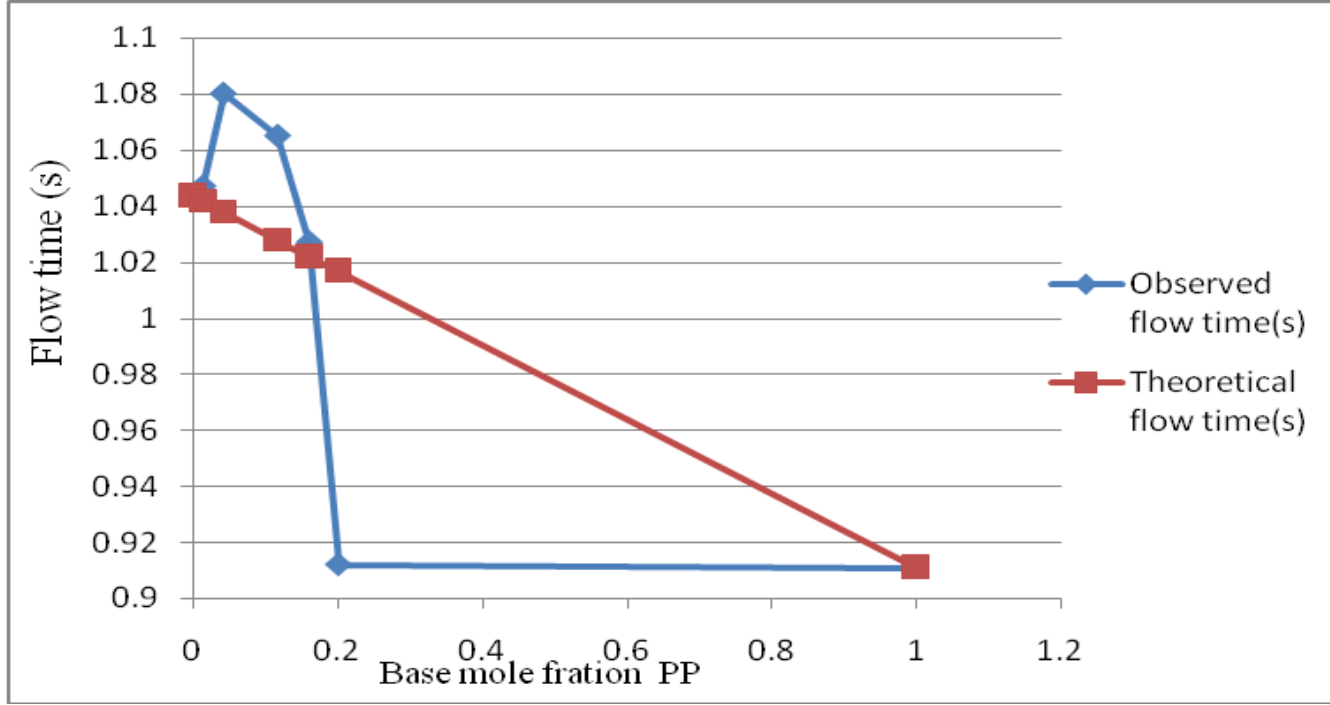

Fig.4: Establishing the degree of interactions of PS:PP in solution

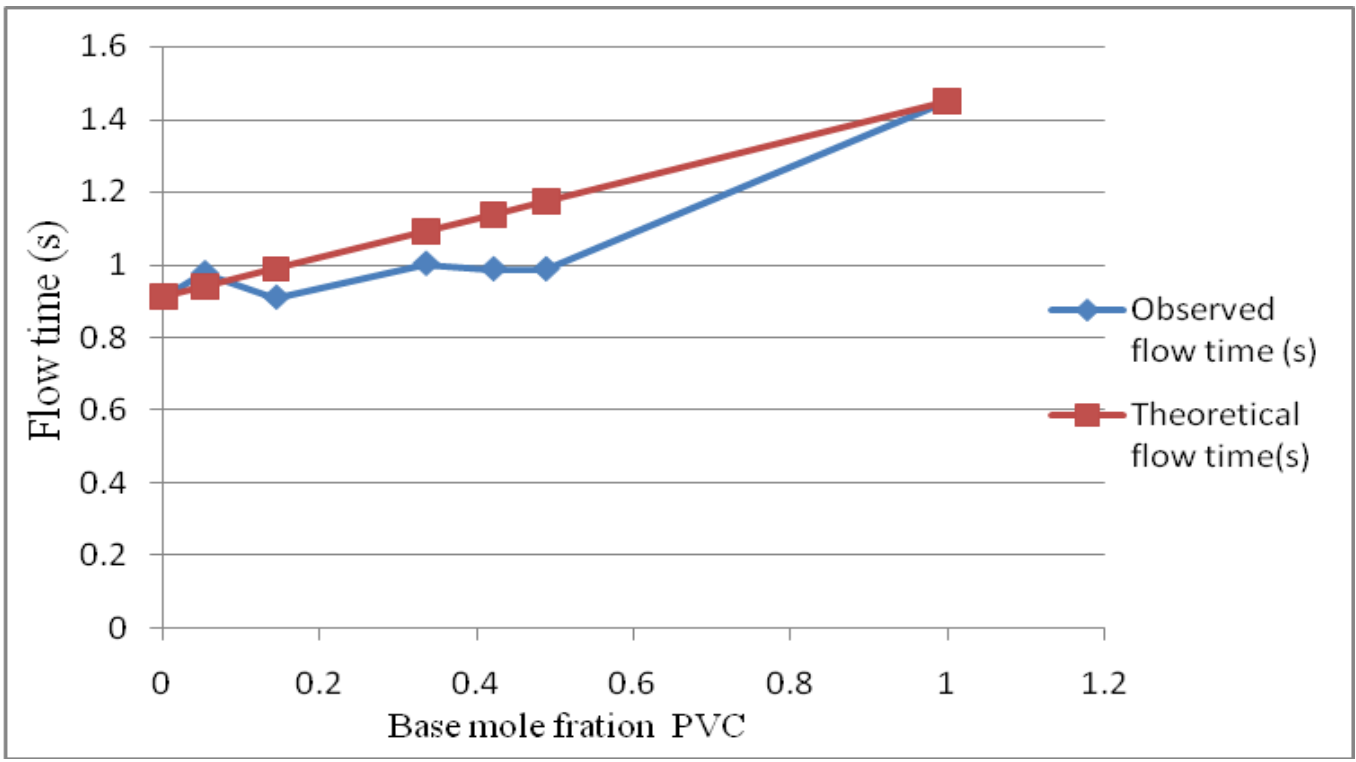

Fig.5: Establishing the degree of interactions of PP:PVC in solution 


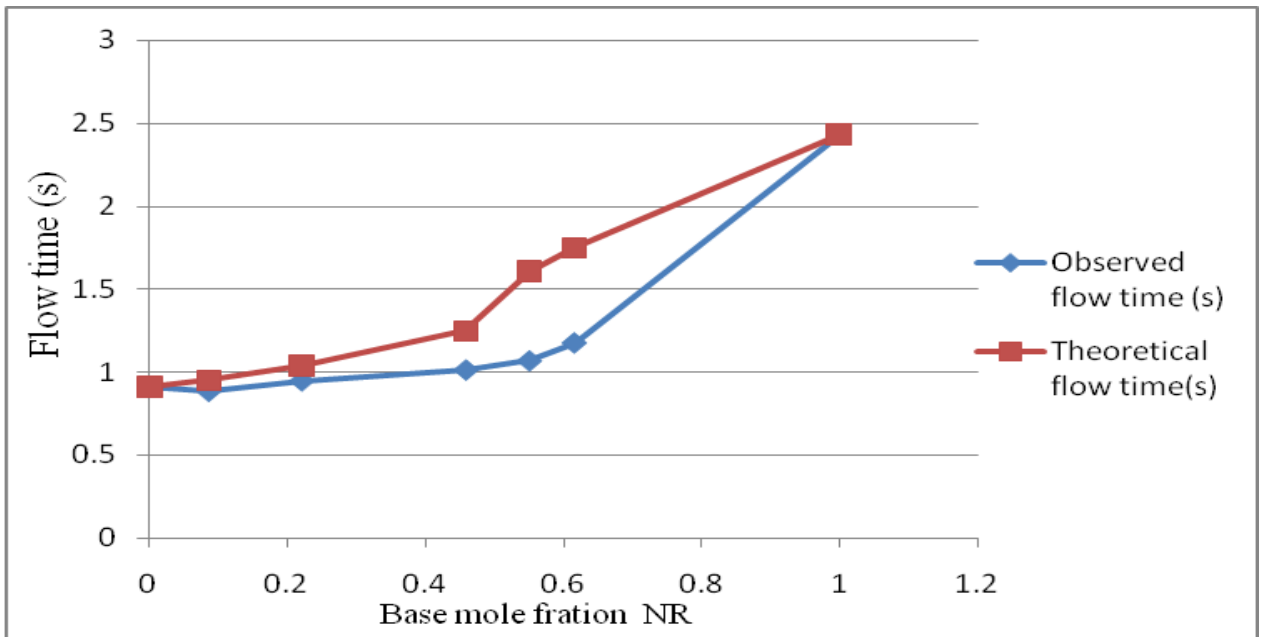

Fig.6: Establishing the degree of interactions of PP:NR in solution

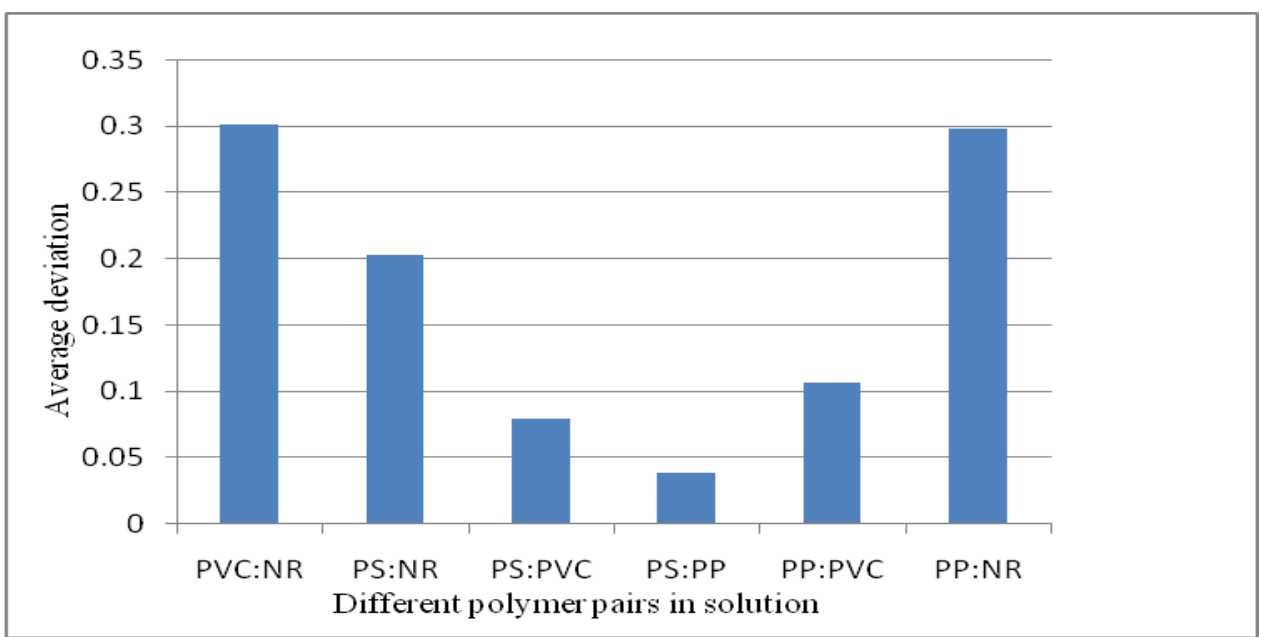

Fig. 7: Comparison of average deviation of polymer blends

\section{CONCLUSIONS}

The four polymers used in this work are common place. The analysis was carried out to show interactions, if any, among the polymer pairs. The results of the analysis indicated that the polymer pairs do interact among themselves in solution. It also revealed that the degrees of interactions vary from one polymer to another. Optimal base molar ratios of maximum interactions are also established, which in most cases are not just points but ranges.

\section{REFERENCES}

[1]. A. N. Eboatu and S. M. Alhaji, Journal of Thermal Analysis, Vol.36, (1990), 2383-2390.

[2]. J. S. Orville. The Science and Technology of Polymer Films. John Wiley and Sons, New York, Vol.2, (1971), p.200

[3]. S. L. Davidson and N. A. Plate, Cord. Chem. Rev., Vol. 16, (1975), p.195

[4]. B. N. Bever. Polymer Blends Encyclopedia of Material Science and Engineering, (Pergamon Press, Oxford, New York, Vol.5, 1988) pp.3654-3659.

[5]. D. Bloor, R. J. Brook, M. C. Fleming and S. Mahajan, Polymer Blends. The Encyclopedia of Advanced Materials (Elsevier Science Ltd., Kidlington England, 1994) pp.2043-2047

[6]. M. J. Folkes and P. S. Hope, Polymer Blends (Chapman and Hall, Glasgow, 1993), pp.46-159 http//www.pscl.ws/mactest/blend.htm (Retrieved Date 15/12/2008)

[7]. A. N. Eboatu, B. Animashaun, S. T. Spiff and Abdulrahman, F. M., Studies on Thermal Characteristics of Polymer Alloys, Journal of Thermal Analysis, Vol.36, (1990), p.85-91

[8]. F. W, Billmeyer, Text Book of Polymer Science $3^{\text {rd }}$ ed., (A Wiley Interscience Publication, John Wiley and Sons, New York, 2003) pp.151-154, 230-232, 345-347

[9]. Neilson, L, E., Mechanical Properties of Polymers (Reinhold, New York, 1963). 